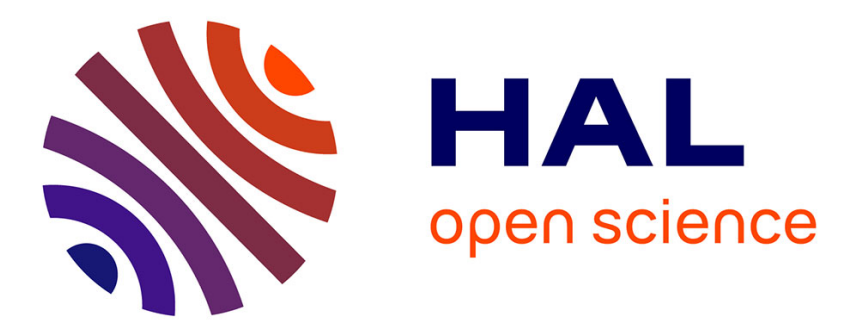

\title{
Effect of space charge on the vacuum electron emission from a microtip
}

\author{
Benjamin Seznec, Tiberiu Minea, Philippe Dessante, Philippe Teste
}

\section{To cite this version:}

Benjamin Seznec, Tiberiu Minea, Philippe Dessante, Philippe Teste. Effect of space charge on the vacuum electron emission from a microtip. 33rd International Vacuum Nanoelectronics Conference (IVNC 2020), Jul 2020, Lyon, France. 10.1109/IVNC49440.2020.9203091 . hal-02985179

\section{HAL Id: hal-02985179 \\ https://hal-centralesupelec.archives-ouvertes.fr/hal-02985179}

Submitted on 2 Nov 2020

HAL is a multi-disciplinary open access archive for the deposit and dissemination of scientific research documents, whether they are published or not. The documents may come from teaching and research institutions in France or abroad, or from public or private research centers.
L'archive ouverte pluridisciplinaire HAL, est destinée au dépôt et à la diffusion de documents scientifiques de niveau recherche, publiés ou non, émanant des établissements d'enseignement et de recherche français ou étrangers, des laboratoires publics ou privés. 


\section{Effect of space charge on the vacuum electron emission from a microtip}

\author{
Benjamin Seznec, Tiberiu Minea \\ Université Paris-Saclay, CNRS, Laboratoire de physique \\ des gaz et des plasmas, 91405, Orsay, France.
}

Email: benjamin.seznec@u-psud.fr

\author{
Philippe Dessante, Philippe Teste \\ Université Paris-Saclay, CentraleSupélec, Sorbonne \\ Universités, CNRS, Laboratoire de Génie Electrique et \\ Electronique de Paris, 91192, Gif-sur-Yvette, France.
}

\begin{abstract}
A model which determines the electron emission from the surface of a microtip has been developed, it solves the multiphysics problem combining the heat transport and the current conservation inside the tip, which is coupled with a Monte Carlo model established to evaluate the electron space charge in front of the tip and to deduce the electric field at the surface of the tip. This modeling approach is versatile and it can be applied for several regimes lying from DC operation to nanosecond pulses.
\end{abstract}

\section{Keywords—modeling, space charge, thermo-field emission}

\section{INTRODUCTION}

Vacuum electron sources exploiting field emission are operated under high voltage, generally in direct current (DC) mode or low frequency. The recent developments of nanosecond pulsed power supplies facilitate the emission of high density electron bursts. However, the electron emission at the surface of a microtip is limited by space charge (SC) when we reach high voltages ( $>20 \mathrm{kV}$ ). A model has been developed to quantify the effects of SC on electron emission and breakdown voltage for different regimes (ns pulse to DC).

\section{NUMERICAL MODEL}

On the cathode, we consider, there is a tip with a hyperbolic shape. His height is equal to $H=10.14 \mu \mathrm{m}$ and the curvature radius at the apex of the tip is equal to $r_{\mathrm{c}}=143 \mathrm{~nm}$. The domain of simulation with the tip is represented in Fig.1a). A 2D axisymmetric model has been developed to determine the current emitted by this tip and to estimate the breakdown voltage. It is a multi-physics model that solves the heat equation and current conservation in the tip and the electric field outside. The equations and boundary conditions for the heat and current equation are detailed in [1]. The emitted current is calculated according Murphy Good's approximation [2].

To determine the electric field distribution in the interelectrode gap (Fig. 1), it is necessary to know the electron distribution in front of the MP, because it gives the source term of the Poisson equation. In vacuum, it depends only on the electron density $n_{\mathrm{e}}$ in this region since none ionization is possible (no gas to be ionized):

$\Delta V_{\text {out }}=-\frac{q_{e} n_{e}}{\varepsilon_{0}}$ $q_{\mathrm{e}}$ and $\varepsilon_{0}$ represent respectively the elementary charge and the vacuum permittivity. Note that our previous work [24] considered Laplace equation instead of Poisson equation, treated here. Knowing the voltage distribution, it is possible to determine the full electric electrostatic field distribution.

$\vec{E}_{\text {out }}(r, z)=-\vec{\nabla} V_{\text {out }}(r, z)$

The height of the domain to determine the electric field is taken equal to $3 H$ (Fig. 1a)) because beyond this distance, the electric field becomes uniform and is given by the macroscopic field. The lateral width of the domain is taken equal to $2 H$, large enough to avoid any side effects. Hence, the boundaries conditions are:

$$
V_{\text {cath }}=\left.0_{i} E_{z}\right|_{\text {Top border }}=-\frac{v_{\text {gnp }}}{a_{\text {gap }}} ;\left.E_{r}\right|_{R \text { Rght border }}=\left.0_{i} E_{r}\right|_{\text {axis }}=
$$
0

(3)

Where $\left.\left.\left.V_{\text {app }} d_{\text {gap } x} E_{z}\right|_{\text {Top bordap }} E_{r}\right|_{\text {Right border }} E_{r}\right|_{\text {axis }}$ represent respectively the applied voltage, the inter-electrode gap (equal to $200 \mu \mathrm{m}$ here), the axial component of the electric field along the top border of the simulation domain, the radial component of the electric field along the right border and the radial component of the electric field along the axis.

In this work, the density in the inter-electrode gap has been obtained from the electron mean density in each mesh during the simulation, following a Monte Carlo (MC) approach detailed hereafter.

Knowing the current distribution at the surface of the tip, it is possible to determine the initial position of the emitted electrons and the number of electrons in each mesh near the surface of the tip. Once out, the trajectory of the electrons is solved in relativistic regime for a small time step $1 \mathrm{fs}$ to meet the Courant Friedrichs Lewy (CFL) criterion. At the end of the simulation, it is possible to know the average number of electrons in each mesh and to deduce an average electron density in each mesh. A new electric field on the surface of the tip is determined and it is possible to solve the temporal heating and cureent conservation equations inside the tip. A new emitted current is deduced. These steps are repeated until the emitted current converges. An example of the electron density for an applied voltage of $38 \mathrm{kV}$ obtained in front of the tip is shown in Figure $1 \mathrm{a}$ ). 


\section{$z, \mu \mathrm{m}$}

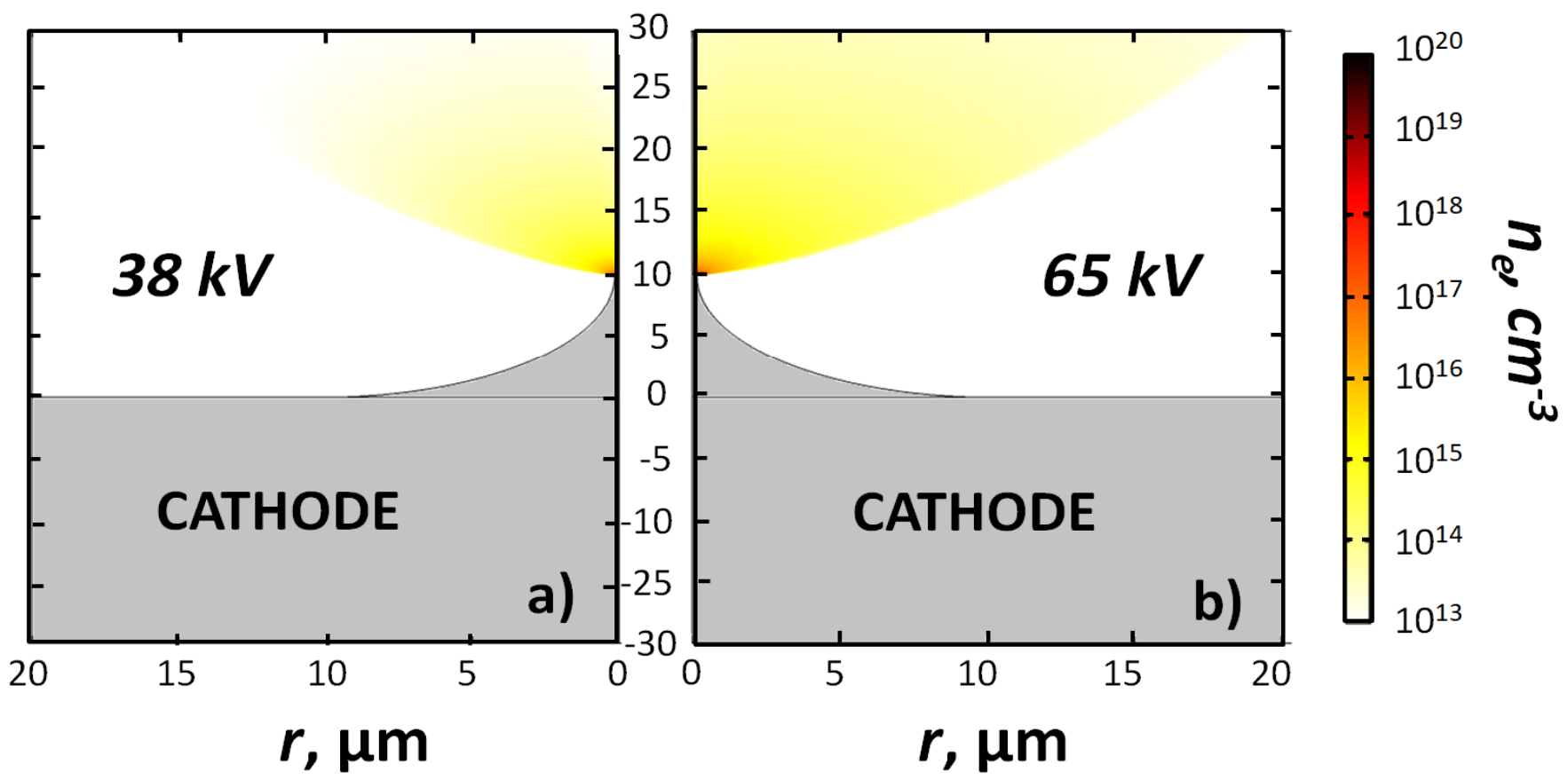

Fig. 1. Domain of simulation and the electron density in the inter-electrode space in front of a tungsten hyperbolic tip at $38 \mathrm{kV}$ (a)) and $65 \mathrm{kV}(\mathrm{b}))$

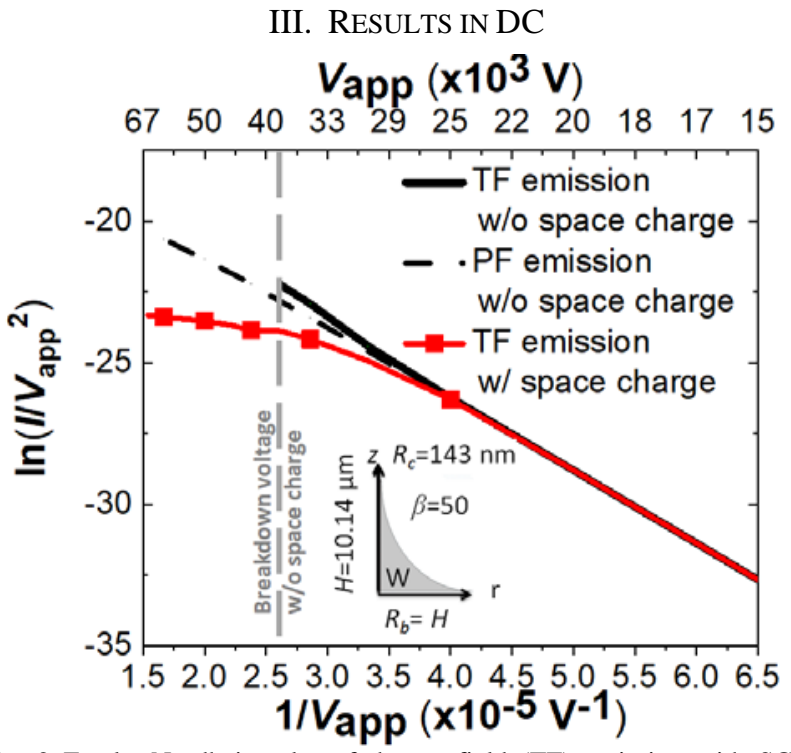

Fig. 2 Fowler-Nordheim plot of thermo-field (TF) emission with SC (red square line) and without SC (black line), for a tungsten hyperbolic MP. The case of Pure Field emission (PF; dot dashed line) corresponds to an electron emission neglecting the thermo-ionic effects. $d_{\mathrm{gap}}=0.2 \mathrm{~mm}$ was kept constant.

It is possible to represent the Fowler-Nordheim plot in cases of pure field (PF) emission and in the case of Thermo-Field emission (TF) with and without taking into account the SC (fig. 2) of a tungsten hyperbolic tip in DC. The black curve is limited to $38 \mathrm{kV}$ because for this voltage, we assume the breakdown to have been reached, because the tip has reached the melting temperature [1]. For low voltages, the curves overlap each other because the tip does not heat up and the electron density in front of the tip is too low to modify the electric field and limit the electron emission.

For higher voltages ( $>25 \mathrm{kV})$, the red square curve becomes saturated because the electron density in front of the tip is high enough to reduce the electric field at the top of the tip and limit the current emitted. Taking into account the space charge, the hyperbolic tungsten tip reaches the melting temperature for a voltage of $65 \mathrm{kV}$, i.e. an increase of $80 \%$ compared to the model without the SC.

By comparing Figures 1a) and b), which represent the electron densities in front of the tip at 38 and $65 \mathrm{kV}$ respectively, the electron density is higher near the tip for $65 \mathrm{kV}$ and stays higher far from the tip.

\section{CONCLUSIONS}

A 2D axisymmetric model describing the electronic emission at the surface of a tungsten hyperbolic tip taking into account the space charge has been developed. It allows in particular to predict the breakdown voltage and to study the trajectory of the electrons in the inter-electrode space. This model allowed us to highlight the significant effect of the space charge on the emitted current and the breakdown voltage.

\section{REFERENCES}

[1] B. Seznec, Ph. Dessante, L. Caillault, J. L. Babigeon, Ph. Teste, and T. Minea, Controlled electron emission and vacuum breakdown with nanosecond pulses, J. Phys. D 49, 235502 (2016).

[2] E. L. Murphy and R. H. Good, Jr., Thermionic emission,field emission, and the transition region, Phys. Rev. 102, 